\title{
SÍNTESE E CARCATERIZAÇÃO DE BETA FOSFATO TRICÁLCICO OBTIDO POR MISTURA A SECO EM MOINHO DE ALTA ENERGIA
}

\author{
T. C. S. PEREIRA ${ }^{1}$ e G. A. FERNANDES ${ }^{2}$ \\ ${ }^{1}$ Universidade Federal de Itajubá, Instituto de Recursos Naturais \\ 2 Universidade Federal de Itajubá, Instituto de Engenharia Mecânica \\ E-mail para contato: thaticsp_ita@hotmail.com
}

\begin{abstract}
RESUMO - O beta fosfato tricálcico ( $\beta$-TCP) é uma cerâmica que possui uma grande gama de aplicação como biomaterial, em função de sua composição química ser muito semelhante à composição do tecido ósseo. A sua obtenção é de fácil elaboração desde que se consiga uma boa homogeneização das matériasprimas. Neste trabalho, estudou-se a obtenção do $\beta$-TCP, pela mistura a seco usando um moinho de alta energia e sua posterior sinterização. As amostras obtidas foram caracterizadas pelos métodos de DRX, FTIR e análise granulométrica. O FTIR mostrou o desaparecimento do carbonato e formação do fosfato quando o material é sinterizado. O DRX confirmou a importância da sinterização pelo aumento da cristalinidade. Sendo que as partículas se aglomeram quando são sinterizadas.
\end{abstract}

\section{INTRODUÇÃO}

O fosfato tricálcico, TCP $\left[\mathrm{Ca}_{3}\left(\mathrm{PO}_{4}\right)_{2}\right]$, é um biomaterial de grande importância, pois como todos os fosfatos de cálcio, apresenta grande semelhança com a fase mineral de ossos e dentes; além de sua excelente biocompatibilidade; bioatividade e ausência de toxicidade local (Gomes et al., 2012).

Sua utilização como biomaterial tem uma grande área de aplicação, pois já fui empregado com sucesso no preenchimento de defeitos e extensão de contornos do tecido ósseo (Billotte, 2000) bem como em sistemas de liberação controlada de fármacos (Lakes, 2000). Sua importância também se deve, ao fato de este ser um dos precursores mais bem sucedidos na síntese de hidroxiapatita, além de ser empregado, em certos casos, em misturas bioativas de estímulo ao crescimento ósseo (Jun et al., 2003).

O TCP pode ser encontrado sob duas formas alotrópicas, $\beta$ e $\alpha$, sendo que a primeira é estável a temperaturas inferiores a $1.125^{\circ} \mathrm{C}$ enquanto que a segunda e formada acima deste patamar (Dorozhkin, 2009).

O $\beta$-TCP (beta fosfato tricálcico) pode ser considerada uma fase de alta temperatura, que é preparado a temperaturas acima de $800^{\circ} \mathrm{C}$ pela decomposição térmica da hidroxiapatita deficiente em cálcio ou por interação no estado sólido de ortofosfato de cálcio acidificado. $\mathrm{O}$ 
$\beta$-TCP não pode ser precipitado de soluções aquosas. Além das rotas de preparação químicas, $\beta$-TCP com íons substituídos pode ser preparado pela calcinação de ossos. (Dorozhkin, 2009).

Este trabalho visou a síntese de $\beta$-TCP, onde as matérias-primas em pó foram misturadas usando moinho planetário de alta energia, de modo a melhorar o contato entre os reagentes.

\section{METODOLOGIA}

O beta fosfato tricálcico foi obtido através da mistura a seco de carbonato de cálcio $(0,35 \mathrm{~mol})$ e fosfato bibásico de cálcio $(0,70 \mathrm{~mol})$, em um moinho planetário de alta energia por 1 h a 200 RPM.

A mistura dos pós foi umidificada com excesso de acetona P.A. e, posteriormente, deixou-se a suspensão descansar por de $24 \mathrm{~h}$. O precipitado foi seco em uma estufa por 24 horas a $80^{\circ} \mathrm{C}$.

O pó obtido de beta-TCP foi desaglomerado em um almofariz de ágata e dividido em duas frações, em seguida foram calcinadas na temperatura de $1000^{\circ} \mathrm{C}$, durante seis horas.

Os pós o foram então submetidos à análise por espectroscopia de infravermelho por transformada de Fourier (FTIR), difração de raios X (DRX) e análise granulométrica.

As fases cristalinas foram identificadas por difração de raios-X. A análise foi conduzida a temperatura ambiente em um equipamento Shimadzu XRD-6000 a $40 \mathrm{kV}$ e $30 \mathrm{~mA}$ e com um comprimento de onda $\lambda \mathrm{CuK} \alpha=0,154 \mathrm{~nm}$. As amostras em forma de pó foi analisada em um intervalo de varredura de $2 \theta$ entre 20 e $80^{\circ}$ a uma taxa de $1,2^{\circ} / \mathrm{min}$.

A análise granulométrica foi realizada a seco em um aparelho da marca Microtrac Inc., modelo 10.6.2.

\section{RESULTADOS E DISCUSSÕES}

\subsection{Resultados dos ensaios de FTIR}

Os espectros de absorção no infravermelho obtidos para a mistura precursora de $\beta$-TCP não calcinada (Figura 1) e calcinada a $1000^{\circ} \mathrm{C}$ (Figura 2), mostram diferenças entre a mistura precursora e a amostra sinterizada, indicando que a sinterização está agindo na estrutura química do biomaterial.

As bandas assinaladas na Figura $1\left(1408,1067\right.$ e $\left.872 \mathrm{~cm}^{-1}\right)$ representam as vibrações $\mathrm{CO}_{3}{ }^{2-}$, proveniente da matéria-prima.

Após a sinterização (Figura 2) o carbonato é eliminado na forma de gases e suas bandas desaparecem dando origem as bandas que representam a formação de fosfatos. Os picos em torno de 943, 1004 e $1115 \mathrm{~cm}^{-1}$ (Figura 2) representam o grupamento $\mathrm{PO}_{4}^{-3}$, que se intensificam com a sinterização; 
Figura 1 - Espectro da mistura precursora do $\beta$-TCP (sem calcinar)

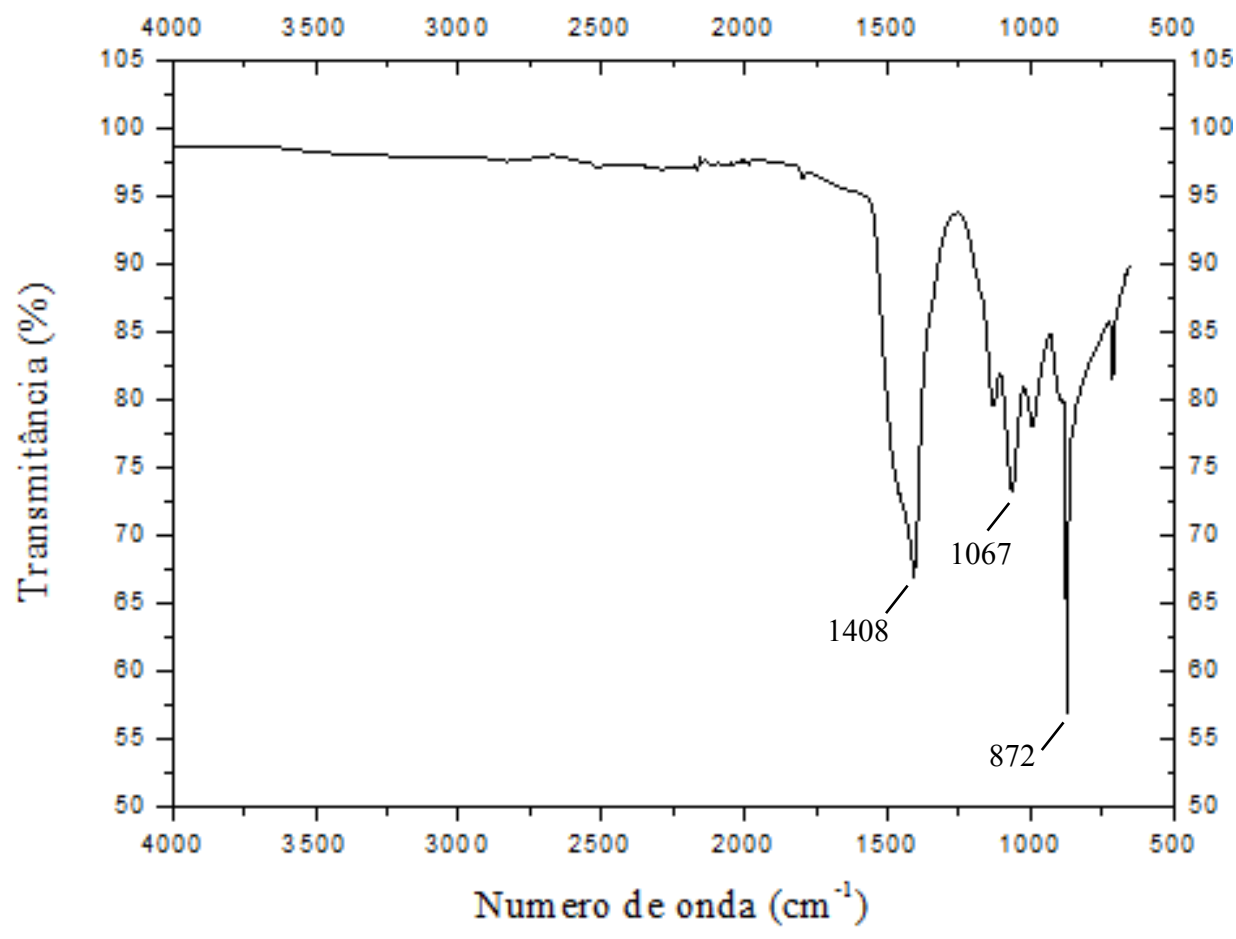

Figura 2 - Espectro da amostra de $\beta$-TCP calcinado a $1.000^{\circ} \mathrm{C}$

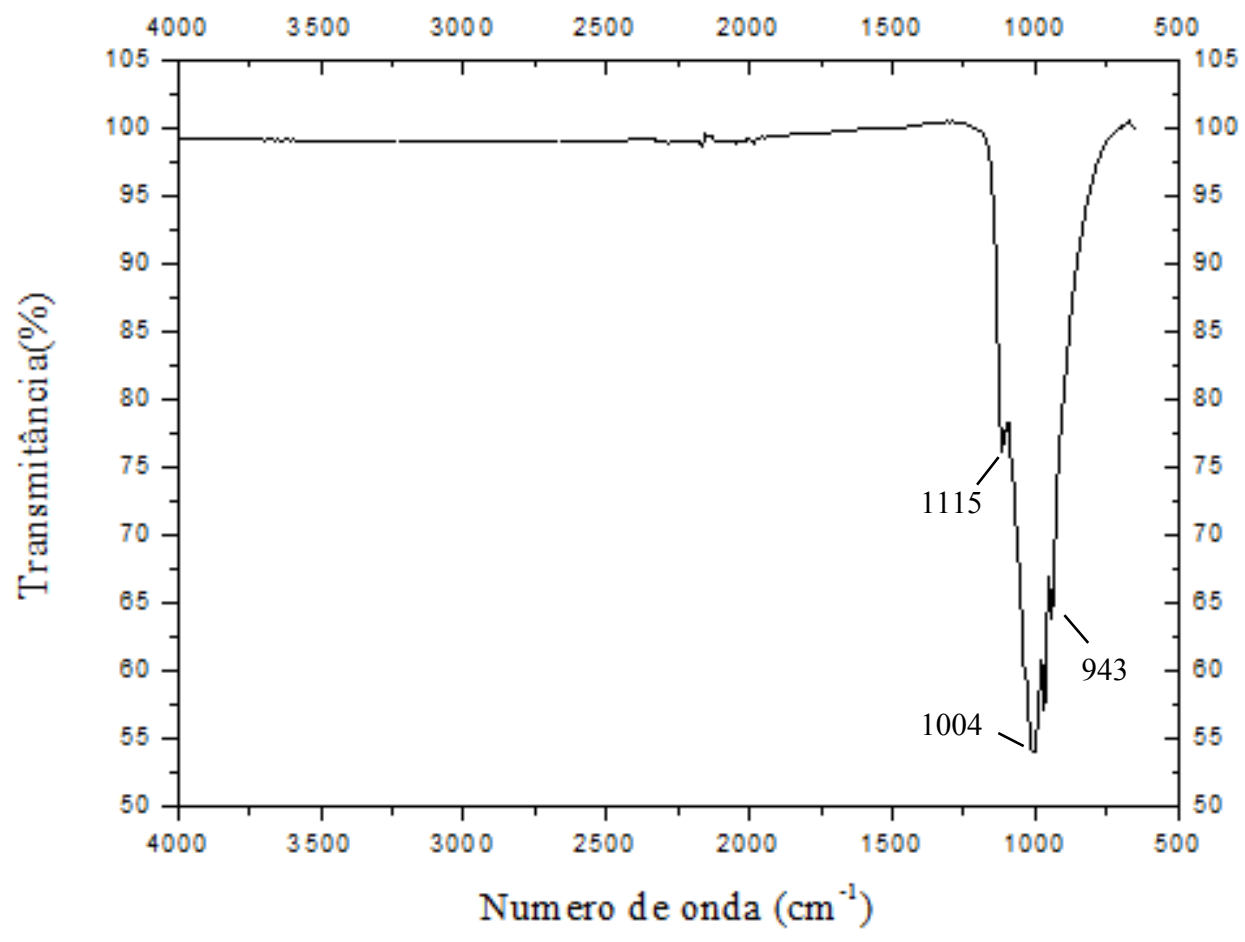




\subsection{Resultados dos ensaios de DRX}

A Figura 4 e a Figura 5 representam os difratogramas de raios-X da mistura precursora e do $\beta$-TCP calcinados a $1000^{\circ} \mathrm{C}$, respectivamente.

Figura 3 - Difratograma da mistura precursora do $\beta$-TCP (sem calcinar)

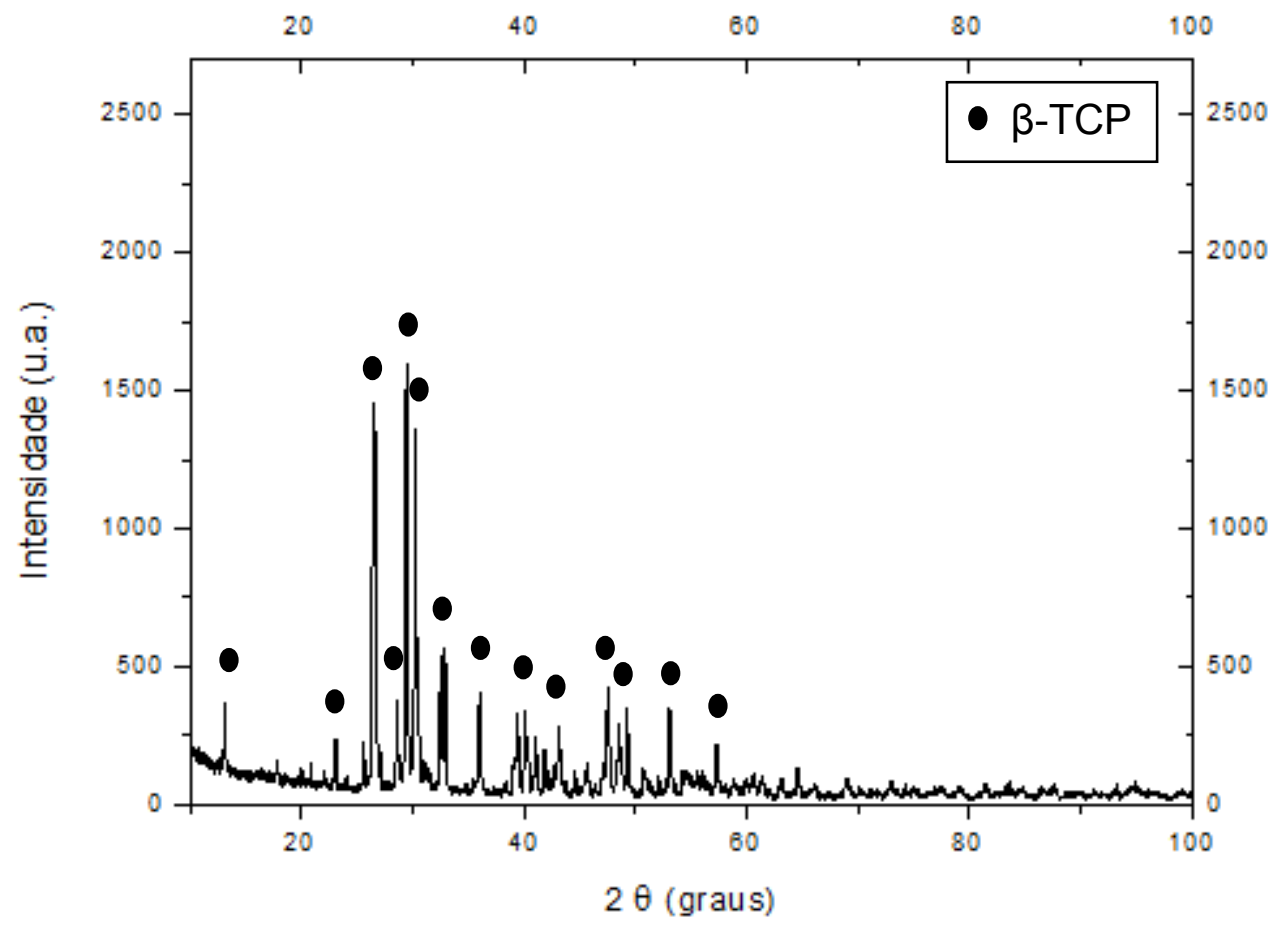

Figura 4 - Difratograma da amostra de $\beta$-TCP calcinada a $1000^{\circ} \mathrm{C}$

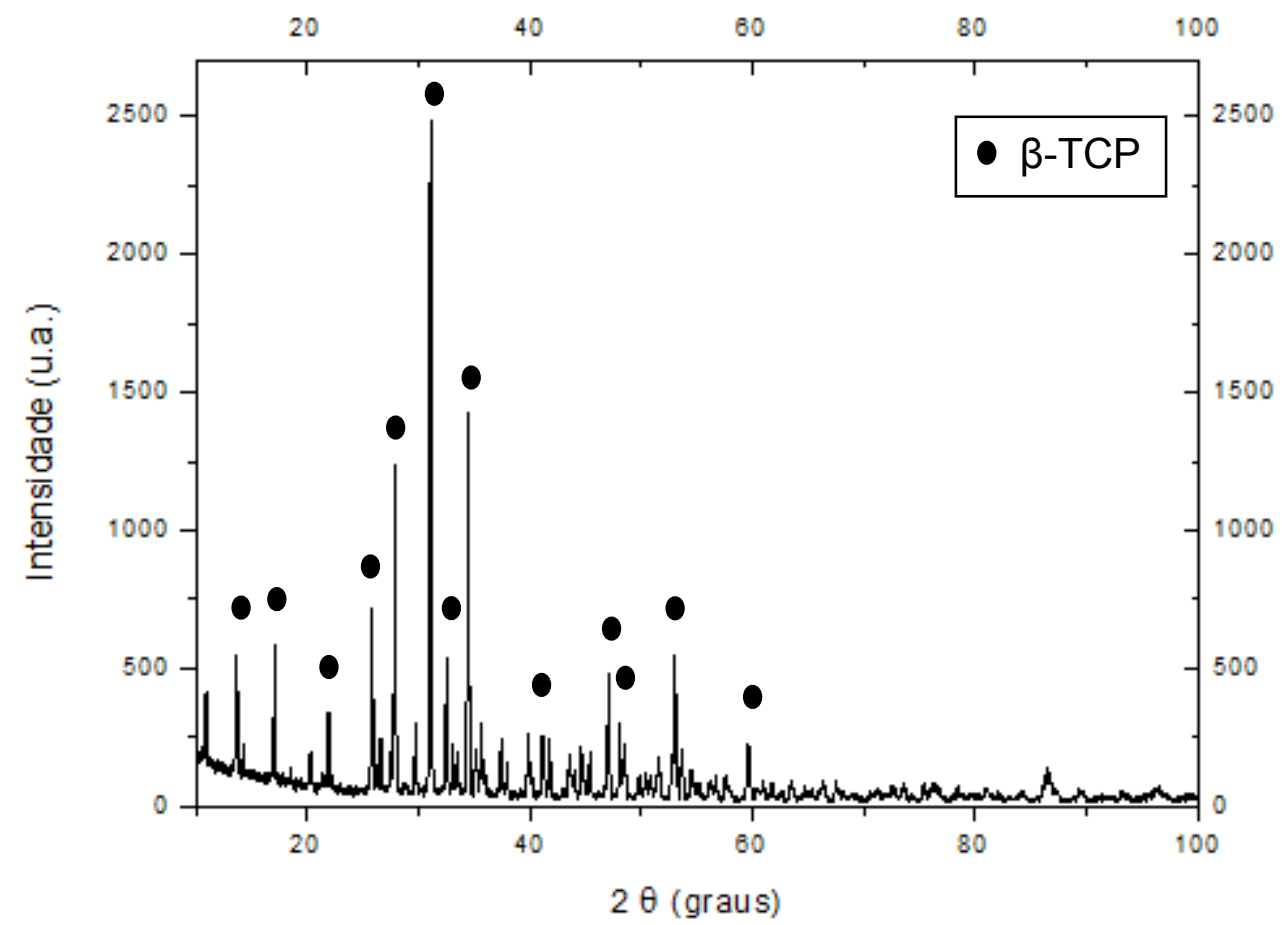


A simples mistura a seco dos reagentes, seguida da mistura a úmido já é suficiente para o surgimento de pequena quantidade de $\beta$-TCP (Figura 3), porém a sinterização é necessário para aumentar a quantidade do biomaterial, como é verificação pelo surgimento de maior quantidade de planos e cristalinos e aumento da intensidade de seus picos (Figura 4).

\subsection{Resultados da análise granulométrica}

A partir da análise granulometrica (Figura 5), obtiveram-se os seguintes valores de diâmetro médio de partículas: $0,921 \mu \mathrm{m}$ para a mistura precursora do $\beta$-TCP e 1,659 $\mu \mathrm{m}$ para o $\beta$-TCP calcinado. A liberação do carbonato na forma de gases e a formação do arranjo cristalino do $\beta$-TCP faz com que as partículas se aglomerem, aumentando assim o tamanho das partículas.

Figura 5 - Distribuição granulométrica para as amostras de $\beta$-TCP, não calcinada e calcinada a $1000^{\circ} \mathrm{C}$

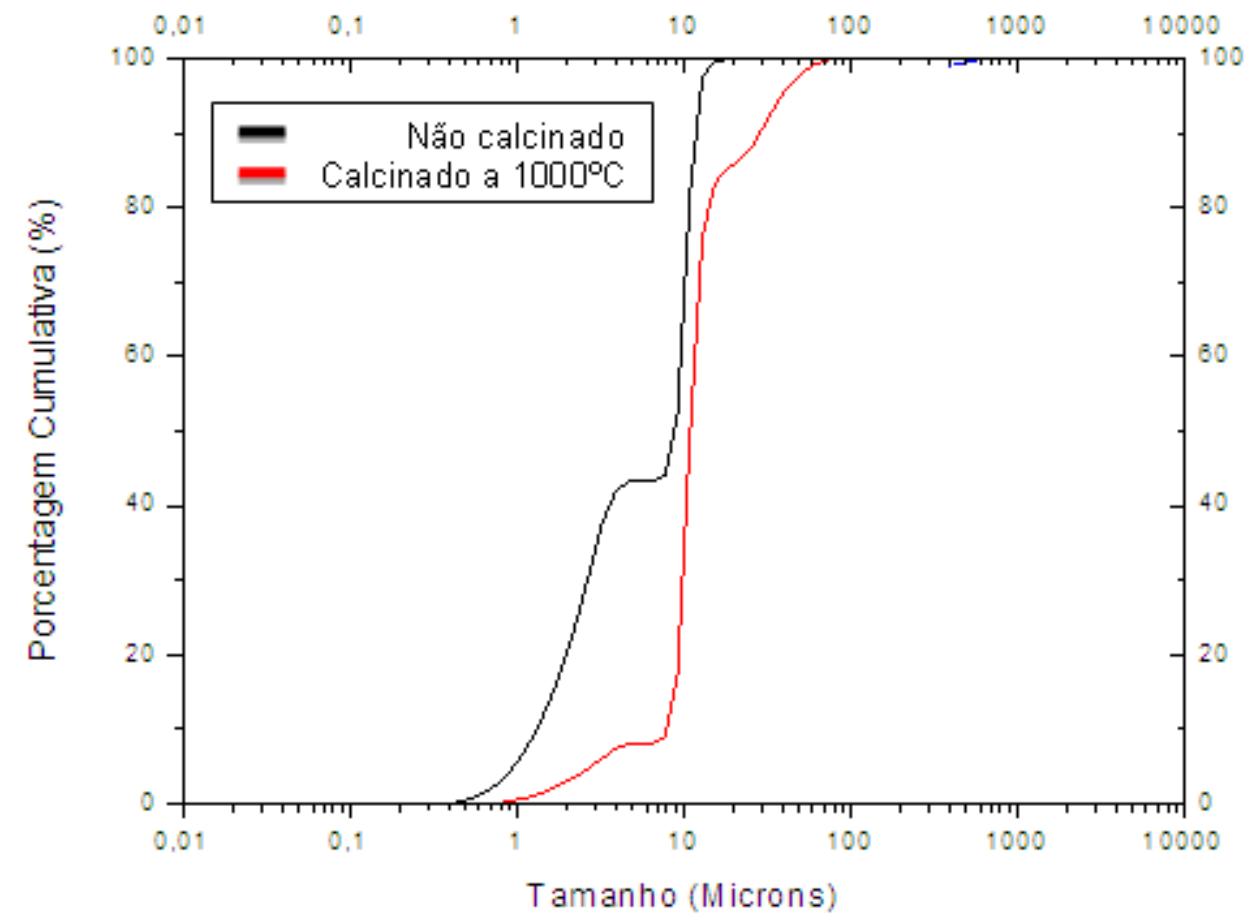

\section{CONCLUSÃO}

O método estudado de síntese do $\beta$-TCP, utilizando uma mistura preliminar a seco em um moinho de alta energia se mostrou bastante eficiente por apresentar um biomaterial com um grau de pureza bastante elevado.

Os ensaios de FTIR e DRX mostraram a necessidade da sinterização para a formação do fosfato de cálcio e aumento da cristalinidade do material.

A analise granulométrica indicou a necessidade de moer o biomaterial formado devido a aglutinação que ocorre após a sinterização. 
Portanto, o método se mostrou bastante eficiente na síntese do $\beta$-TCP.

\section{REFERÊNCIAS}

GOMES, L. C.; DI LELLO, B. C.; CAMPOS, J. B.; SAMPAIO, M.; Síntese e caracterização de fosfatos de cálcio a partir da casca de ovo de galinha. Cerâm., v. 58, p. 448-452, 2012.

BILlotTE, W.G.; Ceramic Biomaterials. Biomedical Engineering Handbook, Boca Raton: CRC Press, 2000.

LAKES, R.; Composite Biomaterials. Biomedical Engineering Handbook, Boca Raton: CRC Press, 2000.

JUN, Y.; KWON, S.; HONG, S.; KIM, H.; Synthesis and dissolution behavior of $\beta$-TCP and HA/ß-TCP composites powders. J. Eur. Ceram. Soc., v. 23, n. 7, p.1039-1045, 2003.

DOROZHKIN, S. V. Calcium orthophosphates in nature, biology and medicine; Mater., v. 2, p. 399-498, 2009. 